\title{
PENCEGAHAN KEJADIAN ISPA PADA ANAK DI DAERAH PENDULANGAN INTAN CEMPAKA BANJARBARU
}

\author{
Lia Yulia Budiarti ${ }^{1}$, Farida Heriyani ${ }^{2}$ \\ ${ }^{1}$ Departemen Mikrobiologi dan Parasitologi Fakultas Kedokteran Universitas Lambung Mangkurat, \\ ${ }^{2}$ Departemen Ilmu Kesehatan Masyarakat Fakultas Kedokteran Universitas Lambung Mangkurat \\ Email penulis : lia_arivin@ymail.com \\ faridaheriyani@yahoo.co.id
}

\begin{abstract}
Abstrak
Penyakit infeksi saluran pernapasan akut (ISPA) masih merupakan salah satu masalah kesehatan masyarakat yang utama dan anak-anak tergolong lebih berisiko untuk terkena ISPA. Salah satu penyebab ISPA adalah kondisi udara yang tercemar. Di wilayah Cempaka Banjarbaru terdapat pendulangan intan yang berkontribusi terhadap pencemaran udara. Kegiatan IbM ini bertujuan untuk memberikan pengetahuan dan pemahaman tentang bahaya polusi udara di daerah pendulangan intan dan memberikan pengetahuan tentang cara pencegahan ISPA pada anak-anak di daerah tersebut disertahi pembagian masker agar dapat digunakan saat keluar rumah agar terhindar dari polusi udara. Metode pelaksanaan berupa pemberian penyuluhan secara langsung kepada anak-anak berada di daerah pendulangan intan disertai pemasangan poster dan pemberian masker. Telah terpasang poster dan dibagikan pamflet tentang polusi udara di daerah pendulangan intan dan pencegahan ISPA pada siswa-siswi dua sekolah dasar di daerah pendulangan intan Kec. Cempaka Banjarbaru. Juga telah dilakukan penyuluhan langsung pada para ibu. Setelah dilakukan kegiatan diperoleh peningkatan pengetahuan para peserta kegiatan tentang polusi udara di daerah pendulangan intan dan pencegahan ISPA pada siswa-siswi dua sekolah dasar di daerah pendulangan intan Kec. Cempaka Banjarbaru. Pada akhir kegiatan juga dibagikan masker pada semua peserta kegiatan.
\end{abstract}

Kata-kata kunci : ISPA, pendulangan intan, siswa SD

\section{PENDAHULUAN}

Penyakit infeksi saluran pernapasan akut (ISPA) masih merupakan salah satu masalah kesehatan masyarakat yang utama. Hal ini disebabkan masih tingginya angka kejadian penyakit ISPA terutama pada balita dan anakanak. Kasus ISPA merupakan $50 \%$ dari seluruh penyakit pada anak. Dari seluruh penyebab kematian balita, proporsi kematian yang disebabkan oleh ISPA mencakup 20-30\%. Kematian ISPA ini sebagian besar disebabkan oleh karena pneumonia (Depkes RI, 2004; Badan Penelitian dan Pengembangan Kesehatan, 2010).
Di Indonesia, ISPA terutama pneumonia menjadi penyebab kematian nomor tiga setelah penyakit kardiovaskuler dan TBC. Menurut laporan WHO sekitar 800.000 hingga 1 juta anak meninggal dunia tiap tahun akibat pneumonia. Pada usia anak-anak, pneumonia merupakan penyebab kematian terbesar terutama di negara berkembang termasuk Indonesia. Adapun angka kesakitan diperkirakan mencapai 250 hingga 299 per 1000 anak setiap tahunnya (Depkes R, 2008; WHO, 2007).

Penyebab tingginya kekambuhan ISPA pada anak terkait dengan banyaknya faktor yang berhubungan dengan ISPA. Beberapa faktor yang berkaitan dengan ISPA pada anak antara lain usia, keadaan gizi yang buruk, status

Kesehatan 552 
imunisasi yang tidak lengkap serta kondisi lingkungan yang buruk seperti ventilasi rumah yang tidak memenuhi syarat, kepadatan hunian rumah yang terlalu padat, pencemaran udara (asap dan debu) di dalam rumah maupun di luar rumah. Pencemaran udara di dalam rumah berasal dari dari asap rokok, asap dapur dan asap dari obat nyamuk yang digunakan di dalam rumah, sementara polusi udara di luar rumah berasal dari gas buangan trasportasi, asap dari pembakaran sampah dan asap dari pabrik dan industi. (Said, 2006; Kazi, 2009).

Industri termasuk kegiatan pertambangan dan pendulangan merupakan salah satu penyumbang polutan penyebab polusi udara. Polutannya dapat berupa asap dan debu yang masuk ke udara. Terdapat bahan-bahan kimia yang terkandung dalam asap tersebut. Hal ini sangat berpengaruh pada kesehatan terutama pada sistem pernapasan manusia bahkan bisa menyebabkan keracunan karena polutan yang tidak bisa di terima oleh tubuh. Bidang industri nampak sebagai penyumbang emisi terbesar kedua setelah kendaraan bermotor. Masuknya polutan udara pertama kali di dalam tubuh akan berpengaruh pada sistem pernapasan manusia (Izzah, 2012).

$\begin{array}{cccr} & \text { Meskipun } & \text { departemen } & \text { kesehatan } \\ \text { sudah } & \text { memiliki } & \text { program } & \text { untuk } \\ \text { penanggulangannya } & \text { yaitu } & \text { Program }\end{array}$
Pemberantasan Penyakit Infeksi Saluran Pernapasan Akut, namun kondisi penyakit ini masih menjadi tantangan serius bagi dunia kesehatan. Pencegahan terhadap penyakit ini juga diharapkan dapat dilaksanakan oleh seluruh masyarakat (Depkes RI, 2004).

ISPA yang terjadi di Provinsi Kalimantan Selatan termasuk dalam sepuluh penyakit terbanyak di setiap puskesmas, termasuk di Puskesmas Cempaka Banjarbaru. Berdasarkan data di Puskesmas Cempaka tahun 2014 didapatkan data bahwa kasus ISPA menempati urutan pertama dalam kunjungan terbanyak di Puskesmas Cempaka. Didapatkan kasus ISPA di Puskesmas Cempaka mencapai sekitar 2.559 kasus yang merupakan kasus penyakit terbanyak setiap tahunnya dan lebih banyak menyerang anak-anak (Badan Penelitian dan Pengembangan Kesehatan. 2010; Puskesmas Cempaka, 2015).

Keadaan tanah di wilayah Kecamatan Cempaka ini sebagian besar terdiri dari tanah yang berbatu-batu dan berpasir yang mengandung bahan galian tambang seperti intan, emas, batubara, koral, pasir, dan lain-lain. Sehingga di wilayah kerja Puskesmas Cempaka ini terdapat banyak daerah pertambangan intan, emas, batubara dan basir. Semua kegiatan pertambangan ini menghasilkan polutan seperti debu baik karena proses pertambangannya sendiri maupun debu yang disebabkan oleh lalulintas kendaraan pengangkut bahan tambang tersebut. Debu yang mencemari udara sehingga berpotensi mempengaruhi kesehatan masyarakat setempat teuutama anak-anak yang lebih rentan karena daya tahannya yang masih rendah. Debu yang banyak di udara luar juga dapat masuk kedalam rumah sehingga membuat udara di dalam rumah ikut tercemar. Orang yang menghisap debu-debu di udara dapat menderita infeksi saluran nafas yang dapat berulang dan menjadi parah karena polusi udara yang cenderung menetap di daerah tersebut (Puskesmas Cempaka, 2015). Agen penyebab pada seorang penderita iISPA dapat terjadi akibat terinhalasinya bakteri -bakteri sebagai kontaminan udara pada lingkungan dalam rumah penderita. Hasil penelitian pendahuluan mengenai jenis bakteri kontaminan udara pada udara di lingkungan rumah penderita infeksi saluran pernapasan, diantaranya yaitu hasil pendahuluan didapatkan adanya beberapa jenis bakteri kontaminan udara yang sama di lingkungan udara rumah penderitaa ISPA dengan jenis bakteri patogen sebagai penyebab infeksi salruran pernapasan pada seorang pendeita (Budiarti, Rahmiati, 2009; Budiarti, 2010)

Berdasarkan laporan Puskesmas Cempaka Kota Banjarbaru dan didukung oleh penelitian Budiarti ketahui bahwa masih tingginya angka kejadian ISPA terutama pada anak-anak . Salah satu penyebabnya adalah tingginya polusi udara yang disebabkan oleh aktivitas pertambangan/pendulangan yang ada di wilayah ini serta aktivitas lalu lintas kendaraan

Kesehatan 553 
yang mengangkut hasil dari pertambangan/pendulangan tersebut Jumlah penduduk di wilayah ini yang tergolong usia anak cukup tinggi jika dibandingkan dengan kelompok usia lainnya dan mayoritas tingkat pendidikan penduduk tergolong sangat rendah.

\section{METODE}

Pendekatan yang dilakukan berupa
pemberian promosi kesehatan berupa
penyuluhan secara langsung kepada anak-anak sekolah dasar yang ada di daerah tersebut mengenai polusi udara akibat pertambangan/pendulangan di daerah tersebut dan akibatnya bagi saluran pernapasan serta pencegahan ISPA pada anak. Selain itu promosi ini dilakukan dengan pemberian poster tentang pencegahan ISPA. Poster-poster ini di tempel di dinding-dinding sekolah sebagai salah satu bentuk promosi kesehatan di sekolah. Kemudian anak-anak juga diberikan masker agar bisa mereka gunakan saat ke luar rumah sebagai salah satu bentuk menghindari polusi udara agar dapat mecegah ISPA.

Lokasi kegiatan bertempat di dua sekolah dasar yang ada di dekat pendulangan intan di Kecamatan Cempaka Banjarbaru. Peralatan yang digunakan terdiri dari poster, pamphlet, spanduk, LCD proyektor dak laptop, lem dan plester, serta masker.

Sebelum kegiatan, terlebih dahulu dilakukan sosialisasi dan koordinasi dengan lurah serta kepala sekolah atau Puskesmas setempat. Sasaran kegiatan diberikan undangan agar dapat berhadir dan mengikuti kegiatan.

Untuk pelaksanaan kegiatan penyuluhan, diawali dengan pemberian pretes pengetahuan para ibu yang menjadi sasaran kegiatan untuk mengetahui pengetahuan awal mereka tentang pencegahan ISPA. Kegiatan dilanjutkan dengan memberikan penyuluhan tentang bahaya polusi udaara akibat pertambangan/pendulangan bagi pernapasan serta bagaimana cara pencegahan ISPA.
Penyuluhan dilakukan dengan metode ceramah ditambah dengan tanya jawab dan diskusi dengan sasaran kegiatan untuk mengetahui pemahaman sasaran kegiatan. Media penyuluhan berupa layar LCD dan pamflet untuk mempemudah pemberian materi dan pemahaman pada sasaran kegiatan.

Yang menjadi sasaran pada kegiatan ini adalah anak-anak di 2 SD di wilayah Kecamatan Cempaka yang berdekatan dengan daerah pertambangan/pendulangan intan, yaitu sebanyak 60 orang anak.

Kegiatan diakhiri dengan pemberian postest kepada peserta menggunakan pertanyaan yang sama dengan pretest untuk mengetahui pemahaman mereka tentang materi penyuluhan dan sebagai salah satu indikator keberhasilan kegiatan ini. Dilanjutkan dengan pemberian masker kepada sasaran kegiatan.

\section{HASIL DAN PEMBAHASAN}

Telah dilaksanakan kegiatan pengabdian masyarakat berupa pemberian promosi kesehatan berupa penyuluhan secara langsung kepada anak-anak sekolah dasar yang ada di daerah pendulangan intan Kecamatan Cempaka Banjarbaru mengenai polusi udara akibat pertambangan/pendulangan di daerah tersebut dan akibatnya bagi saluran pernapasan serta pencegahan ISPA pada anak. Selain itu promosi ini dilakukan dengan pemberian poster tentang pencegahan ISPA. Poster-poster ini di tempel di dinding-dinding sekolah sebagai salah satu bentuk promosi kesehatan di sekolah.

Kemudian anak-anak juga diberikan masker agar bisa mereka gunakan saat ke luar rumah sebagai salah satu bentuk menghindari plusi udara agar dapat mecegah ISPA. Kegiatan di lakukan di 2 sekolah dasar yaitu SDN 2 Sungai Tiung dan SDN 3 Sungai Tiung Kecamatan Cempaka yang terletak di dekat pendulangan intan dan siswa-siswinya merupakan penduduk di daerah pendulangan intan tersebut. Kegiatan bertujuan untuk meningkatkan pengetahuan dan kesadaran siswa-siswi SD tentang pencegahan ISPA 
sehingga dapat menurunkan angka kejadian ISPA pada anak sekolah dasar di daerah pendulangan intan Kecamatan Cempaka Banjarbaru.

Untuk pelaksanaan kegiatan penyuluhan, diawali dengan pemberian pretes pengetahuan para siswa-siswi yang menjadi sasaran kegiatan untuk mengetahui pengetahuan awal mereka tentang pencegahan ISPA. Peserta kegiatan terdiri dari 30 orang siswa Kelas V dan Kelas VI SDN 2 Sungai Tiung dan 30 orang siswa-siswi kelas V dan VI SDN 3 Sungai Tiung Kec. Cempaka Banjarbaru. Berikut disajikan hasil pretest pengetahuan siswa tentang pencegahan ISPA :

Tabel 1. Hasil pretest pengetahuan siswa tentang polusi udara dan pencegahan ISPA

\begin{tabular}{ccc}
\hline Pengetahuan & $\begin{array}{c}\text { Jumlah } \\
\text { peserta }\end{array}$ & $\begin{array}{c}\text { Persentase } \\
(\%)\end{array}$ \\
\hline Baik & 2 & 3,33 \\
\hline Cukup & 11 & 18,33 \\
\hline Kurang & 47 & 78,34 \\
\hline Jumlah & 60 & 100 \\
\hline
\end{tabular}

Berdasarkan tabel 1 diketahui bahwa sebagain besar $(78,33 \%)$ peserta kegiatan mempunyai pengetahuan jelek tentang pencegahan ISPA, hanya $18,33 \%$ peserta mempunyai pengetahuan cukup dan hanya $3,33 \%$ atau 2 orang yang mempunyai pengetahuan baik. Hal ini menunjukkan bahwa masih rendahnya pengetahuan para siswa-siswi tentang pencegahan ISPA. Sehingga berdasarkan data ini sangat diperlukan adanya pemberian promosi kesehatan kepada anak-anak sekolah dasar yang ada di daerah pendulangan intan Kecamatan Cempaka Banjarbaru mengenai polusi udara akibat pertambangan/pendulangan di daerah tersebut dan akibatnya bagi saluran pernapasan serta pencegahan ISPA pada anak.

$$
\text { Kegiatan dilanjutkan dengan }
$$

memberikan penyuluhan tentang bahaya polusi udaara akibat pertambangan/pendulangan bagi pernapasan serta bagaimana cara pencegahan ISPA. Penyuluhan dilakukan dengan metode ceramah ditambah dengan tanya jawab dan diskusi dengan sasaran kegiatan untuk mengetahui pemahaman sasaran kegiatan. Media penyuluhan berupa layar LCD dan pamflet yang dibagikan kepada semua peserta untuk mempemudah pemberian materi dan pemahaman pada sasaran kegiatan.

Kegiatan diakhiri dengan pemberian postest kepada peserta menggunakan pertanyaan yang sama dengan pretest untuk mengetahui pemahaman mereka tentang materi penyuluhan dan sebagai salah satu indikator keberhasilan kegiatan ini. Berikut disajikan hasil posttest tentang polusi udara dan pencegahan ISPA :

Tabel 2. Hasil postest pengetahuan siswa tentang polusi udara dan pencegahan ISPA

Pengetahuan Jumlah Persentase (\%)
peserta

\begin{tabular}{ccc}
\hline Baik & 53 & 88,33 \\
\hline Cukup & 6 & 10,00 \\
\hline Kurang & 1 & 1,67 \\
\hline Jumlah & 60 & 100 \\
\hline
\end{tabular}

Berdasarkan tabel 2 diketahui tingkat penyuluhan peserta setelah dilakukan penyuluhan. Didapatkan bahwa sebagian besar peserta $(88,33 \%)$ telah memiliki pengetahuan yang baik dan 6 orang $(11,67 \%)$ memiliki pengetahuan yang cukup. Hanya 1 orang yang memiliki pengetahuan yang kurang tentang polusi udara dan pencegahan ISPA.

Nilai ini menunjukkan bahwa setelah dilakukan penyuluhan secara langsung telah terjadi peningkatan pengetahuan tentang polusi udara dan pencegahan ISPA pada para siswasiswi yang menjadi peserta kegiatan ini. Jadi dapat diambil kesimpulan bahwa kegiatan promosi berupa penyuluhan langsung tentang polusi udara dan pencegahan ISPA telah berhasil dilaksanakan.

Kegiatan dilanjutkan dengan pembagian masker kepada seluruh peserta kegiatan sebagai contoh dan dapat digunakan peserta saat berada di udara dengan polusi udara atau saat mereka sedang menderita ISPA untuk mencegah penularan kepada teman-temannya. Kegiatan diakhiri dengan pembagian dan pemasangan poster tentang polusi udara dan pencegahan ISPA di dinding sekolah sebagai salah satu media promosi kesehatan bagi siswa- 
siswi di sekolah tersebut agar pesannya dapat berlanjut.

Industri termasuk kegiatan pertambangan dan pendulangan merupakan salah satu penyumbang polutan penyebab polusi udara. Polutannya dapat berupa asap dan debu yang masuk ke udara. Terdapat bahan-bahan kimia yang terkandung dalam asap tersebut. Hal ini sangat berpengaruh pada kesehatan terutama pada sistem pernapasan manusia bahkan bisa menyebabkan keracunan karena polutan yang tidak bisa di terima oleh tubuh. Bidang industri nampak sebagai penyumbang emisi terbesar kedua setelah kendaraan bermotor. Masuknya polutan udara pertama kali di dalam tubuh akan berpengaruh pada sistem pernapasan manusia (Izzah, 2012).

$\begin{array}{lccr} & \text { Meskipun } & \text { departemen } & \text { kesehatan } \\ \text { sudah } & \text { memiliki } & \text { program } & \text { untuk } \\ \text { penanggulangannya } & \text { yaitu } & \text { Program }\end{array}$
Pemberantasan Penyakit Infeksi Saluran Pernapasan Akut, namun kondisi penyakit ini masih menjadi tantangan serius bagi dunia kesehatan. Pencegahan terhadap penyakit ini juga diharapkan dapat dilaksanakan oleh seluruh masyarakat (Depkes RI, 2004).

\section{KESIMPULAN}

Dengan telah dilakukannya kegiatan Pencegahan Kejadian ISPA pada Anak di daerah Pendulangan Intan Kecamatan Cempaka Banjarbaru dan dapat berhasil meningkatkan pengetahuan peserta tentang polusi udara dan pencegahan ISPA disertai pembagian pamphlet dan masker serta pembagian dan pemasangan poster pencegahan ISPA di dua sekolah dasar di daerah pendulangan intan Kec. Cempaka Banjarbaru.

Kegiatan dapat dilanjutkan dengan sasaran yang lebih luas bagi masyarakat yang tinggal di daerah pendulangan intan Kec.Cempaka Banjarbaru agar dapat mengurangi angka kejadian ISPA di masyarakat daerah tersebut.

\section{REFERENSI}

Badan Penelitian dan Pengembangan Kesehatan. 2010. Hasil Riset Kesehatan Dasar (RISKESDAS) Nasional tahun 2010.

Budiarti L.Y.,. 2010. Pola Bakteri Sumber Infeksi Nosokomial Di Rumah Sakit Umum Ratu Zalecha Martapura. Jurnal Seminar PERMI Kalsel: 27 September 2010.

Budiarti, L.Y., Rahmiati, Linda M.S.,, 2009. Jenis Bakteri Kontaminan Udara di Bangsal Bedah RSUD Ulin Banjarmasin Periode Agustus - September 2008. Laporan Hasil Penelitian. FK Unlam (Laporan tersimpan di perpustakaan ).

Depkes RI. 2004. Kajian Riset Operasional Intensifikasi Pemberantasan Penyakit Menular Tahun 1998/1999-2003. Jakarta: Depkes.

Depkes RI. 2011. Buku Bagan Manajemen Terpadu Balita Sakit (MTBS). Jakarta: Depkes RI.

Izzah, NM. 2012. Dampak Polutan dari Asap Pabrik terhadap Sistem Pernapasan Manusia Kaitannya dengan Toksikologi. Malang : Universitas Negeri Malang.

Kazi. 2009. Risk Factors for Acute Respiratory Infections (ARI) Among Children Under Five Years in Bangladesh. Journal of Scientific Research; 72(81).

Kemenkes RI, Ditjen PP\&PL. 2011. Pedoman Pengendalian Infeksi Saluran Pernapasan Akut. Jakarta: Kemenkes RI.

Puskesmas Cempaka. 2016. Laporan Tahunan Puskesmas Cempaka Banjarbaru.

Said M. 2006. Pneumonia Penyebab Utama Mortalitas Anak Balita di Indonesia. Buletin IDAI; 45, TH XXVI.

WHO. 2007. Infection Prevention and Control of Epidemic-and Pandemic-Prone Acute Respiratory Diseases in Health Care. Jenewa: WHO 
